\title{
Cordycepin induces apoptosis in human liver cancer HepG2 cells through extrinsic and intrinsic signaling pathways
}

\author{
LE-WEN SHAO ${ }^{1}$, LI-HUA HUANG ${ }^{1}$, SHENG YAN $^{2}$, JIAN-DI JIN ${ }^{3}$ and SHAO-YAN REN ${ }^{3}$ \\ ${ }^{1}$ Nursing Department; Departments of ${ }^{2}$ Hepato-Biliary-Pancreatic Surgery and ${ }^{3}$ Infectious Disease, \\ The First Affiliated Hospital, College of Medicine, Zhejiang University, Hangzhou, Zhejiang 310003, P.R. China
}

Received March 6, 2015; Accepted April 12, 2016

DOI: 10.3892/ol.2016.4706

\begin{abstract}
Cordycepin, also termed 3'-deoxyadenosine, is a nucleoside analogue from Cordyceps sinensis and has been reported to demonstrate numerous biological and pharmacological properties. Our previous study illustrated that the anti-tumor effect of cordycepin may be associated with apoptosis. In the present study, the apoptotic effect of cordycepin on HepG2 cells was investigated using 4',6-diamidino-2-phenylindole, tetraethylbenzimidazolylcarbocyanine iodide and propidium iodide staining analysis and flow cytometry. The results showed that cordycepin exhibited the ability to inhibit HepG2 cells in a time- and dose-dependent manner when cells produced typical apoptotic morphological changes, including chromatin condensation, the accumulation of sub-G1 cells and change mitochondrial permeability. A potential mechanism for cordycepin-induced apoptosis of human liver cancer HepG2 cells may occur through the extrinsic signaling pathway mediated by the transmembrane Fas-associated with death domain protein. Apoptosis was also associated with $\mathrm{Bcl}-2$ family protein regulation, leading to altered mitochondrial membrane permeability and resulting in the release of cytochrome $c$ into the cytosol. The activation of the caspase cascade is responsible for the execution of apoptosis. In conclusion, cordycepin-induced apoptosis in HepG2 cells involved the extrinsic and intrinsic signaling pathway and was primarily regulated by the Bcl-2 family proteins.
\end{abstract}

\section{Introduction}

Cordyceps militaris is a fungus that parasitizes Lepidoptera larvae and has been extensively used as a folk tonic food and crude drug (1). Cordyceps militaris has long been considered

Correspondence to: Dr Li-Hua Huang, Nursing Department, The First Affiliated Hospital, College of Medicine, Zhejiang University, 79 Qingchun Road, Hangzhou, Zhejiang 310003, P.R. China E-mail: zjhuanglihua@yeah.net

Key words: Cordyceps sinensis, cordycepin, antitumor, apoptosis, HepG2 to have natural medicinal properties, such as anti-angiogenic, anti-tumor, anti-viral, anti-inflammatory and hypoglycemic effects (1-8).

Cordycepin, also termed 3'-deoxyadenosine, is a nucleoside analogue from $C$. militaris (9) and has been reported to demonstrate numerous notable biological and pharmacological properties, including immunological stimulation, anti-cancer and anti-viral effects (10-15), a stimulating effect on interlukin-10 production as an immune modulator (16) and preventing hyperlipidermia (17).

Apoptosis, also termed programmed cell death, is a key regulator of tissue homeostasis and is characterized by typical morphological and biochemical hallmarks, including cell shrinkage, membrane blebbing, chromatin condensation and nuclear fragmentation (18). The mechanisms for foreign chemicals disrupting cell functions and causing tissue damage have been associated with the triggering of apoptosis signal transduction pathways, consisting of the intrinsic (mitochondrial) and extrinsic (death receptor) pathways (19).

Although cordycepin has been shown to have a cytotoxic effect on HepG2 cells, the detailed molecular mechanisms have not been well elucidated $(17,19)$. In the present study, the mechanistic understanding of how cordycepin mediates apoptosis in HepG2 cells was investigated and the intrinsic and extrinsic apoptosis pathways were the main focus.

\section{Materials and methods}

Materials. Dried Cordyceps militaris was purchased from Cordyceps Garden Biotechnology Company (Fuzhou, China). The macroprous adsorption resin NKA-II was purchased from the Chemical Plant of Nankai University (Tianjin, China). Sulforhodamine B (SRB), 4',6-diamidino-2-phenylindole (DAPI), propidium iodide (PI) and tetraethylbenzimidazolylcarbocyanine iodide (JC-1) were purchased from Sigma-Aldrich (St. Louis, MO, USA). The following antibodies were purchased from Sangon Biotech Co., Ltd. (Shanghai, China): Mouse monoclonal anti-Fas (1:3,000; catalog no. D198888); rabbit polyclonal anti-Fas ligand (1:3,000; catalog no. D262701); mouse monoclonal anti-Fas associated with death domain protein (FADD; 1:3,000; catalog no. D199671); rabbit polyclonal anti-caspase-8 (1:2,000; catalog no. D155240); rabbit polyclonal anti-caspase-9 (1:2,000; catalog no. D220078); rabbit ployclonal anti-caspase-10 (1:2,000; catalog no. 
D260010); rabbit monoclonal anti-caspase-3 (1:3,000; catalog no. D120074); mouse monoclonal anti-B-cell lymphoma-2 (Bcl-2; 1:3,000; catalog no. D198628); rabbit polyclonal antiBcl-2 associated X protein (Bax; 1:3,000; catalog no. D120073); mouse monoclonal anti-BH3 interacting domain death agonist (Bid; 1:3,000; catalog no. D198911); and rabbit polyclonal anti-cytochrome $c(1: 2,000$; catalog no. D110006). Rabbit polyclonal anti-mouse $\operatorname{IgG}(1: 3,000$; catalog no. sc-358920) and goat anti-rabbit IgG (1:3,000; catalog no. sc-2768) antibodies were purchased from Santa Cruz Biotechnology, Inc. (Dallas, TX, USA). The Mitochondrial Membrane Potential Assay kit with JC-1, radioimmunoprecipitation assay (RIPA) lysis buffer and Cell Mitochondria Isolation kit were purchased from Beyotime Institute of Biotechnology (Haimen, China).

Cell lines and culture. HepG2 cell lines were purchased from the Culture Center of the Institute of Basic Medical Sciences of the Chinese Academy of Medical Sciences (Beijing, China). The cells were maintained in Dulbecco's modified Eagle's medium (DMEM; Gibco; Thermo Fisher Scientific, Inc., Waltham, MA, USA) supplemented with $10 \%$ fetal bovine serum (Invitrogen; Thermo Fisher Scientific, Inc.), 100 IU/ml penicillin and $100 \mu \mathrm{g} / \mathrm{ml}$ streptomycin (Sigma-Aldrich), and cultured at $37^{\circ} \mathrm{C}$ for $48 \mathrm{~h}$ in a humidified atmosphere consisting of $95 \%$ air and $5 \% \mathrm{CO}_{2}$.

Isolation and purification of cordycepin. A total of $150 \mathrm{~g}$ dried fruiting bodies of $C$. militaris were cleaned with distilled water, dried in a dark and ventilated place and crushed prior to soaking in $500 \mathrm{ml}$ distilled water overnight at room temperature, and then boiled in distilled water for $3 \mathrm{~h}$. Subsequent to filtration to remove debris, the filtrate (crude aqueous extract) was concentrated in a rotary evaporator (model no.0010001820; IKA $^{\circledR}$ Works Guangzhou, Guangzhou, China). Ethanol was added and the mixture was left at room temperature overnight. The precipitate obtained subsequent to filtration was discarded and the supernatant was lyophilized to yield the crude sample. The crude extract was chromatographed on a NKA-II column (Sigma-Aldrich) and eluted with $50 \%$ (v/v) ethanol to collect the fractions, which were then further purified by high performance liquid chromatography (HPLC). The Lab Alliance HPLC system (model no. 2690/2695; Waters Technologies Ltd., Shanghai, China), including two Series III pumps (model no. 90-2489 rev M; Scientific Systems, Inc. State College, PA, USA) and anabsorbance detector (model no. 500; Waters Technologies Ltd.) set at $254 \mathrm{~nm}$, connected to a Cs420 Hardware integrator (model no. Cs420; Waters Technologies Ltd.). The column was a 250x10 mm reversed-phase Merck Millipore C18 ODS column (Merck Millipore, Darmstadt, Germany) with an internal diameter of $12 \mu \mathrm{m}$. The temperature was set at $30^{\circ} \mathrm{C}$ and the elution conditions were as follows: Flow rate, $0.8 \mathrm{ml} / \mathrm{min}$; and solvent, $15 \%$ methanol.

Antiproliferative activity assay of cordycepin. Various concentrations of cordycepin $(0,125,250$ and $500 \mu \mathrm{M})$ were inoculated into 96-well microplates when the cell concentration was adjusted to $1 \times 10^{5}$ cells $/ \mathrm{ml}$. Cultures in triplicate were treated with cordycepin for $48 \mathrm{~h}$ and the control wells received only maintenance medium (DMEM). Cellular responses were colorimetrically evaluated by an SRB assay. Briefly, the cells were fixed with 25\% trichloroacetic acid (Sigma-Aldrich) and washed and stained with $0.4 \%$ SRB. Subsequent to the cell-bound SRB being solubilized by the addition of $10 \mathrm{mM}$ Tris-HCl, bound SRB was colorimetrically assessed using an ELISA microplate reader (MK3; Thermo Fisher Scientific, Inc.) at $490 \mathrm{~nm}$. Cell growth inhibition was expressed as a percentage of the untreated control absorbance following the subtraction of the mean background absorbance. Compounds were considered to have potent growth inhibitory activity when the reduction in SRB absorbance was $>25 \%$ compared with the untreated control cells. The half maximal inhibitory concentration $\left(\mathrm{IC}_{50}\right)$ values were calculated from the dose-response curves.

Assessment of apoptosis by DAPI staining. HepG2 cells were seeded into a $50 \mathrm{ml}$ culture flask at a density of $1 \times 10^{5}$ cells $/ \mathrm{ml}$ for $24 \mathrm{~h}$. Subsequent to treatment with or without cordycepin $(0,125,250$ and $500 \mu \mathrm{M})$ at $37^{\circ} \mathrm{C}$ for $48 \mathrm{~h}$, the cells were collected and washed with phosphate-buffered saline (PBS). Cell pellets were fixed with $4 \%$ paraformaldehyde for $10 \mathrm{~min}$ and washed three times with PBS. The cells were then incubated with $5 \mu \mathrm{g} / \mathrm{ml}$ DAPI for $20 \mathrm{~min}$. Subsequent to washing with PBS, the cells were observed under a fluorescence microscope (model no. Bx51; Olympus Corporation, Tokyo, Japan) and images were captured.

Assessment of apoptosis by flow cytometry. HepG2 cells cultured with or without cordycepin at $37^{\circ} \mathrm{C}$ for $48 \mathrm{~h}$ were harvested, washed with PBS and fixed with $70 \%$ cold ethanol at $4^{\circ} \mathrm{C}$ for $4 \mathrm{~h}$. The fixed cells were washed and stained with a PI solution containing $20 \mu \mathrm{g} / \mathrm{ml}$ PI and $10 \mathrm{mg} / \mathrm{ml}$ RNase (Takara Biotech, Inc., Dalian, China) in PBS for $20 \mathrm{~min}$ in the dark. The stained cells were then analyzed by flow cytometry using fluorescence-activated cell sorting (FACS) and the FACSCalibur system (BD Biosciences, Franklin Lakes, NJ, USA). In addition, subsequent to being treated with various concentrations of cordycepin $(0,125,250$ and $500 \mu \mathrm{M})$ for $48 \mathrm{~h}$, the harvested HepG2 cells were washed in PBS and incubated in a freshly prepared JC-1 solution at $37^{\circ} \mathrm{C}$ for $20 \mathrm{~min}$. Cell-associated fluorescence was also measured by FACS.

Western blot analysis. HepG2 cells were treated for $48 \mathrm{~h}$ with various concentrations of cordycepin $(0,125,250$ and $500 \mu \mathrm{M})$ and harvested and lysed in RIPA lysis buffer that contained $1 \%$ NP-40, $0.5 \%$ sodium deoxycholate and $0.1 \%$ SDS. The cell lysates were resolved by sodium dodecyl sulfate-polyacrylamide gel electrophoresis and electrophoretically transferred to a polyvinylidene fluoride membrane, and then blocked for $1 \mathrm{~h}$ with $5 \%$ fat-free milk in PBS with Tween-20 (PBST) at room temperature. The membrane was immunoblotted overnight with antibodies in PBST at $4^{\circ} \mathrm{C}$. Subsequent to being washed with PBST, the membrane was detected by enhanced chemiluminescence (Kodak, Rochester, NY, USA). Equal loading was confirmed by probing with an antibody against $\beta$-actin (1:3000; catalog no. sc-8432; Santa Cruz Biotechnology, Inc.). Mitochondrial and cytosolic fractions were prepared in order to detect cytochrome $c$. Following treatment with the indicated concentrations of cordycepin for $48 \mathrm{~h}, \mathrm{HepG} 2$ cells were harvested and disposed using the Cell Mitochondria Isolation kit, according to the manufacturer's protocol. Finally, the mitochondrial pellet and cytosolic 
supernatant were separated using a centrifuge (model no. 5415C; Eppendorf, Hamburg, Germany).

\section{Results}

Isolation and purification of cordycepin. Two fractions from crude extract, termed A and B, were eluted using NKA macroporous resin (data not shown). Fraction A was then purified on a HPLC preparative column followed by an analytical column using $\mathrm{CH}_{3} \mathrm{OH}: \mathrm{H}_{2} \mathrm{O}=15: 85$ (v/v) as the mobile phase. The retention time of fraction $\mathrm{A}$ was $\sim 10.5 \mathrm{~min}$, which is consistent with that of standard cordycepin (Fig. 1A). In addition, mass spectrometric analysis revealed that the $\mathrm{m} / \mathrm{z}$ of fraction $\mathrm{A}$ was 252.1096 Da, which corresponds with the $\mathrm{m} / \mathrm{z}$ of standard cordycepin (Fig. 1B).

Effect of cordycepin on HepG2 cell viability. Cordycepin exhibited the ability to inhibit the proliferation of HepG2 cells in a time- and dose-dependent manner (Fig. 2). The $\mathrm{IC}_{50}$ values for HepG2 cells treated with cordycepin for 24, 48, 72 and $96 \mathrm{~h}$ were $735 \pm 3.67,497.5 \pm 2.49,385 \pm 1.93$ and $307.5 \pm 1.54 \mu \mathrm{M}$, respectively.

Assessment of apoptosis by DAPI staining. The fluorescence microscopic examination with DAPI staining revealed that morphological changes, such as chromatin condensation, nuclear shrinkage or fragmentation and apoptotic body formation, occurred in HepG2 cells subsequent to being treated with cordycepin for $48 \mathrm{~h}$ (Fig. 3A).

Assessment of apoptosis by flow cytometry. The flow cytometric analysis with PI staining revealed that the cells treated with various concentrations of cordycepin for $48 \mathrm{~h}$ exhibited an apoptotic hypodiploid sub-G1 peak in a concentration-dependent manner (Fig. 3B). The flow cytometric analysis with JC-1 staining showed the respective green fluorescence intensity ratios, which indicated the apoptotic HepG2 cells, were 5.72, 18.58, 32.12 and $36.65 \%$, respectively (Fig. 4).

Cordycepin-induced apoptosis signaling pathway. Cordycepin increased the expression levels of Fas and FADD, but had no effect on FasL expression. Additionally, the level of procaspase- 8 decreased, while the level of cleaved caspase- 8 was elevated (Fig. 5A). The expression of the Bcl-2 family proteins was also detected and the results showed that cordycepin enhanced the expression level of truncated Bid (tBid) and decreased the level of Bid, but had little effect on the levels of Bax and Bcl-2 (Fig. 5B). A decreased level of cytochrome $c$ was detected in the mitochondrial fraction and an increased level was detected in the cytosolic fraction (Fig. 5C). Furthermore, the results also showed that HepG2 cells treated with cordycepin for $48 \mathrm{~h}$ underwent significant cleavage of precaspase-9 and precaspase-3 (Fig. 5C).

\section{Discussion}

As a natural compound, cordycepin plays a key role in cancer therapy and induces apoptosis in numerous cells by targeting molecules and pathways (20-22). However, studies investigating the induction of apoptosis by cordycepin through the

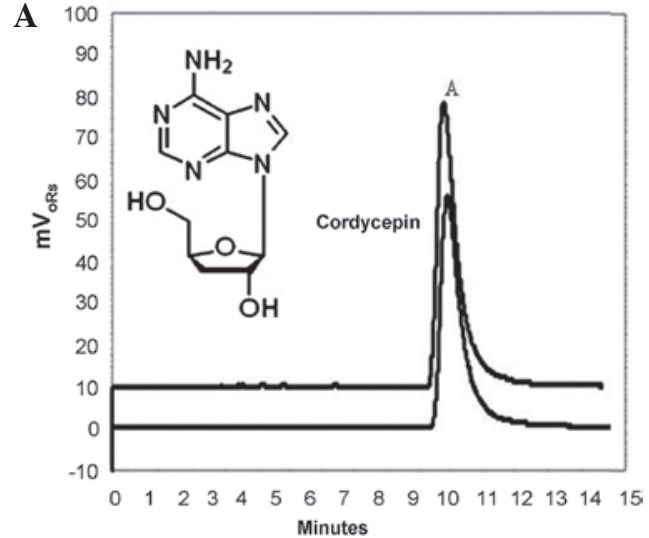

B

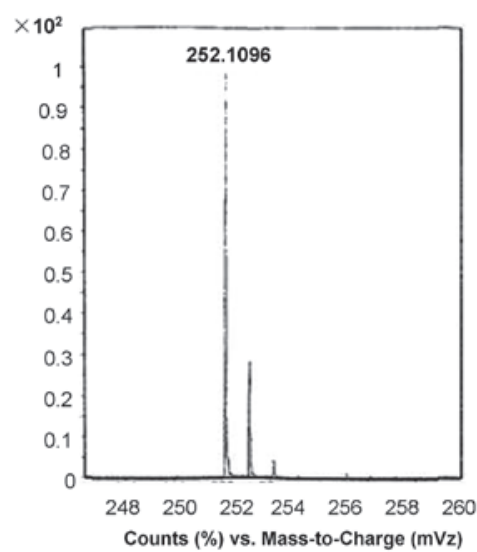

Figure 1. HPLC and MS analysis of cordycepin. (A) HPLC assay. The retention time of fraction A was $10.5 \mathrm{~min}$, which corresponds with the retention time of cordycepin. (B) MS assay. The m/z of fraction A was 252.1096 Da, which is consistent with the $\mathrm{m} / \mathrm{z}$ of standard cordycepin. HPLC, high performance liquid chromatography; MS, mass spectrometric.

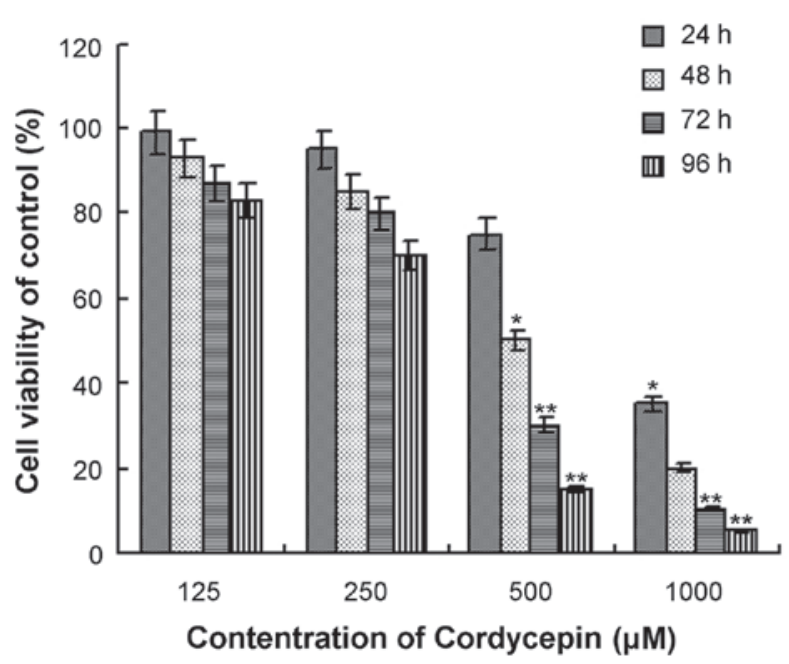

Figure 2. Antiproliferative effect of cordycepin on HepG2 cells. The cell viability of HepG2 cells were measured subsequent to treatment with the indicated concentrations of cordycepin for 24, 48, 72 and $96 \mathrm{~h}$. Cordycepin produced growth inhibitory effects on HepG 2 cells. ${ }^{*} \mathrm{P}<0.05,{ }^{* * *} \mathrm{P}<0.01$ vs. $24 \mathrm{~h}$ cordycepin treatment.

extrinsic and intrinsic signaling pathways in HepG2 cell are currently available $(21,22)$. The present study investigated the effect of cordycepin on HepG2 cells and the molecular pathway by which cordycepin induces apoptosis. Subsequently, 
A

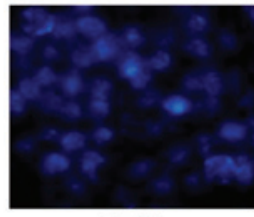

$0 \mu \mathrm{M}$

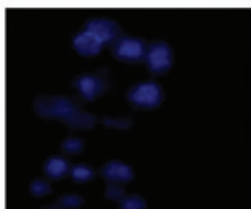

$250 \mu \mathrm{M}$

B
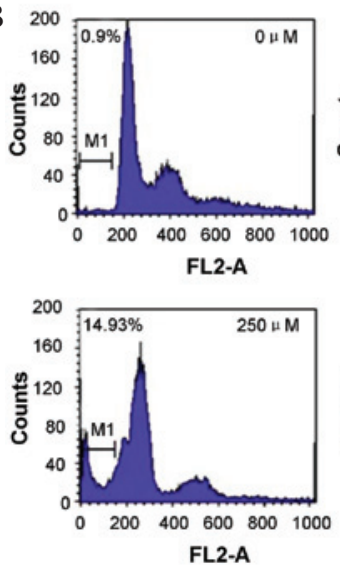

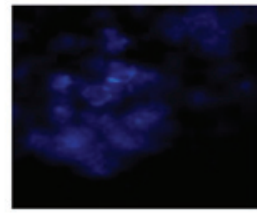

$125 \mu \mathrm{M}$

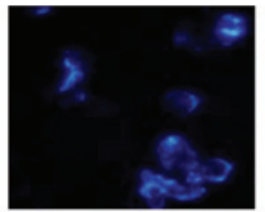

$500 \mu \mathrm{M}$

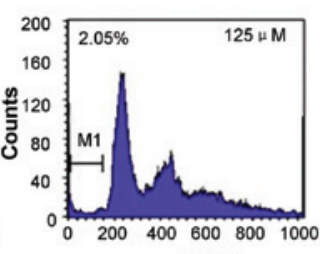

FL2-A

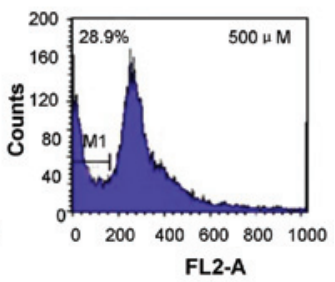

Figure 3. Analysis of the effect of cordycepin on HepG2 cells by DAPI and PI staining. (A) Effect of cordycepin on HepG2 cells, as determined by DAPI staining. HepG2 cells were fixed and stained with DAPI and the nuclear morphology of the cells was then examined with a fluorescence microscope subsequent to treatment for $48 \mathrm{~h}$ with the indicated concentrations of cordycepin. Cytoplasmic shrinkage and nuclear condensation were observed in the cordycepin group, due to the increased fluorescent intensity compared with the control group. (B) Effect of cordycepin on the sub-G1 proportion of HepG2 cells, as determined by PI staining. HepG2 cells were fixed and stained with PI for flow cytometric analysis subsequent to treatment for $48 \mathrm{~h}$ with the indicated concentrations of cordycepin. The percentage of cells with a hypodiploid DNA content (sub-G1) represent those fractions undergoing apoptotic DNA fragmentation. DAPI, 4',6-diamidino-2-phenylindole; PI, propidium iodide.
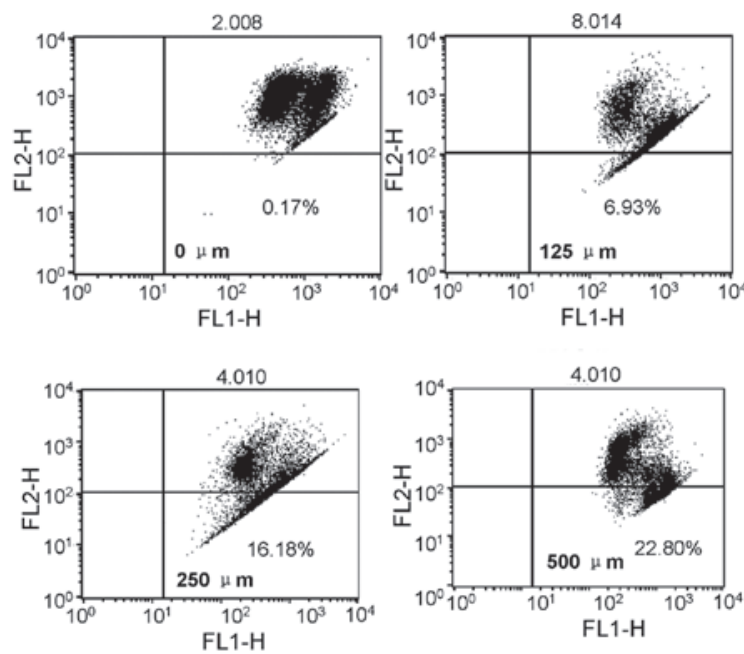

Figure 4. Mitochondrial membrane potential, as assessed by JC-1 staining. HepG2 cells were fixed and stained with JC-1 staining for a flow cytometric analysis subsequent to treatment for $48 \mathrm{~h}$ at the indicated concentrations of cordycepin.
A

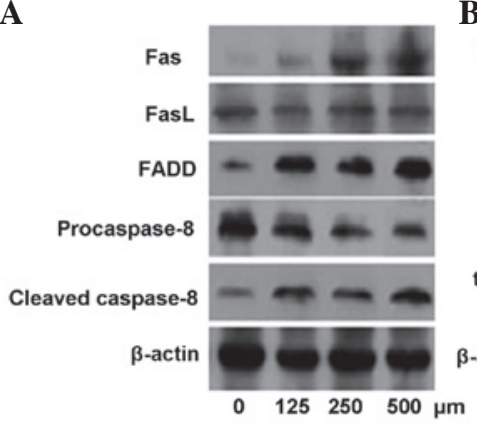

B

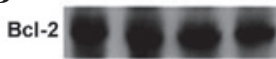

$\mathrm{Bax}$

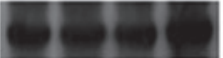

Bid

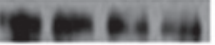

t-Bid

-actin
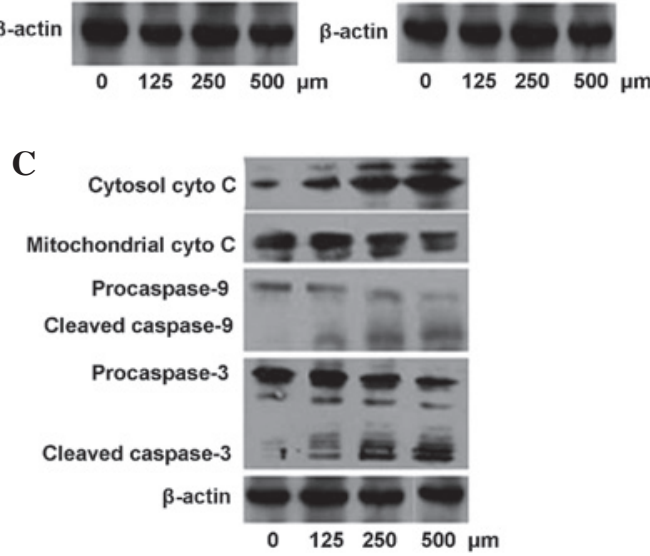

Figure 5. Western blot analysis of the signaling pathway involved in cordycepin-induced apoptosis. (A) Effects of cordycepin on the expression levels of Fas, FasL, FADD and caspase-8. (B) Effects of cordycepin on the expression level of the Bcl-2 family proteins. (C) Effects of cordycepin on the expression level of cyto C, caspase-9 and caspase-3. FasL, Fas ligand; FADD, Fas-associated death domain protein; Bcl-2, B-cell lymphoma-2; Bax, Bcl-2-associated X protein; Bid, $\mathrm{BH} 3$ interacting domain death agonist; t-Bid, truncated Bid; cyto C, cytochrome $c$.

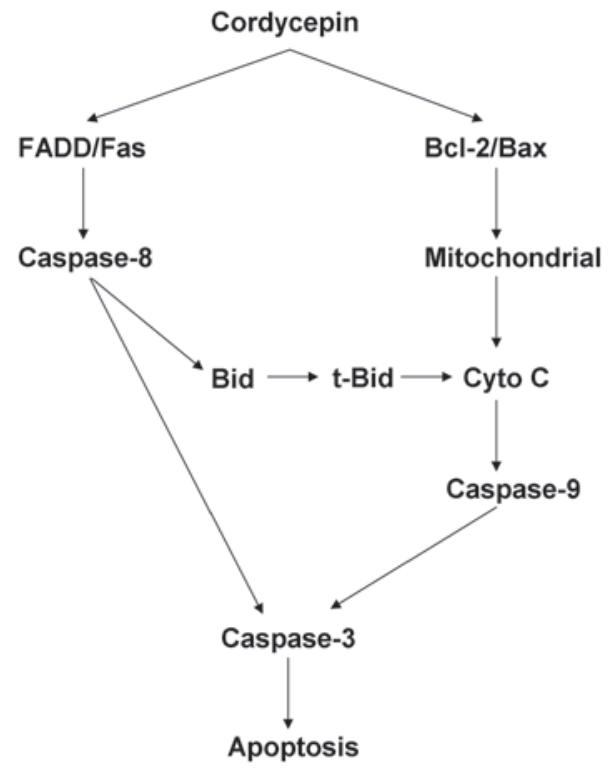

Figure 6. Overview of the pathways involved in cordycepin-induced apoptosis in HepG2 cells. FADD, Fas-associated death domain protein; Bcl-2, B-cell lymphoma-2; Bax, Bcl-2-associated X protein; Bid, BH3 interacting domain death agonist; t-Bid, truncated Bid; cyto $\mathrm{C}$, cytochrome $c$.

it was demonstrated that cordycepin induced apoptosis by the activation of caspase, interaction between Fas and FADD, and modulation of the protein levels of Bid and tBid.

It is well known that mitochondria play a major role in several stress-induced cell death pathways, and damage to 
mitochondria with subsequent loss of mitochondrial membrane potential has been known to be the point of no return in apoptotic cascades $(20,23)$. In the present study, it was found that cordycepin had an inhibitory effect on the viability of HepG2 cells by DAPI staining and could increase the fraction of sub-G1 cells by PI staining. The JC-1 assay also revealed that cordycepin-induced collapse of the mitochondrial membrane occurred in a concentration-dependent manner. All these findings demonstrated that cordycepin may induce apoptosis in HepG2 cells.

In mammalian cells, apoptosis occurs via either the extrinsic (receptor-dependent) or the intrinsic (mitochondria-dependent) pathway, with each involving caspase activation. Fas is a TNF-receptor that transduces the apoptotic signal into cells $(23,24)$. FADD is an apoptotic adaptor molecule that recruits caspase- 8 or caspase-10 to activated Fas (25). FasL is a cytokine that binds to Fas, and it has been proposed that Fas-mediated apoptosis involves the interaction between Fas and FasL (26). In the present study, cordycepin increased the expression levels of Fas and FADD, without changing the level of FasL, and the expression of cleaved caspase- 8 was elevated. Therefore, the present study hypothesizes that cordycepin may stimulate Fas/FADD signaling independently of FasL and subsequently activate caspase- 8 in HepG2 cells.

Fas may induce caspase-mediated cleavage of p22 Bid into a major p15, and minor p13 and p11 product; the major proteolytic product p15 tBid allows the release of cytochrome $c$ (27-29). The mitochondrial membrane potential was shown to be decreased by the JC-1 staining analysis and confirmed the increased cytosolic cytochrome $c$ by western blotting. The activation cascade of caspase-9 and caspase-3, which are responsible for apoptosis execution, was detected. In particular, caspase-3 plays a central role in the execution of apoptosis and its activation requires the activation of initiator caspases, such as caspase- 8 or caspase-9, in response to pro-apoptotic stimuli (30). Caspase- 8 is crucial for triggering apoptosis via the death receptor pathway and its activation requires the binding of death ligands to death receptors (31). In addition, in the prior time course assay, the active forms of caspase- 8 was detected notably earlier than that of caspase-3 and -9 , which clearly demonstrated that caspase- 8 may act as an upstream initiator and the extrinsic pathway was involved in cordycepin-induced apoptosis.

The Bcl-2 family proteins play an essential role in apoptotic progress, such as Bcl-2 protein (anti-apoptosis) and Bax protein (pro-apoptosis). These proteins are regulators of mitochondrial membrane permeability and intermembrane space protein efflux, according to the opposing fractions of the anti-apoptosis members and pro-apoptosis members $(32,33)$. Bax accelerates programmed cell death and undergoes a conformational change that causes translocation to the mitochondrial membrane, leading to the release of cytochrome $c$, which then triggers apoptosis (34). Cordycepin enhanced the expression level of Bax and decreased the expression level of Bid in the present study.

Cleaved Bid causes cytochrome $c$ efflux from mitochondria, which in turn leads to the activation of caspase- 9 and caspase-3 (35). In addition, other Bcl-2 family molecules, such as the proapoptotic protein Bax and anti-apoptotic protein $\mathrm{Bcl}-2$, are also key regulators of apoptosis, which control the release of mitochondrial cytochrome $c$ by modulating the permeability of the outer mitochondrial membrane (36). The upregulation of the ratio of $\mathrm{Bax} / \mathrm{Bcl}-2$ caused by cordycepin was confirmed by immunoblotting. The release of cytochrome $c$ from mitochondria was also relevant to the dissipation of the mitochondrial membrane potential $(\Delta \Psi \mathrm{m})(37)$. In the present study, cordycepin treatment caused a significant decrease of $\Delta \Psi \mathrm{m}$ in HepG2 cells and increased cytosolic cytochrome $c$. These findings indicated that activation of caspase-3 in cordycepin-induced apoptosis may result from direct caspase- 8 cleavage and caspase-8-mediated caspase-3 activation through the intrinsic pathway, which is regulated by the Bcl-2 family proteins.

It has been shown that cordycepin is an analogue of adenosine (22). The possibility that the adenosine receptor is involved in the apoptosis of certain types of cancer cells, including ovarian (38), breast (39) and renal (40) cancer cells, has also been proposed. Thus, additional studies investigating whether cordycepin induces apoptosis through adenosine receptors in HepG2 cells may be valuable.

In conclusion, cordycepin-induced apoptosis in HepG2 cells may be initiated by the FADD mediated signal pathway and regulated by the Bcl-2 family proteins that can change the alternation of mitochondrial membrane permeability and cause the mitochondria mediated apoptosis signal pathway (Fig. 6). To the best of our knowledge, the present study is the first to report apoptosis induced by cordycepin in human liver cancer HepG2 cells.

\section{References}

1. Won SY and Park EH: Anti-inflammatory and related pharmacological activities of cultured mycelia and fruiting bodies of Cordyceps militaris. J Ethnopharmacol 96: 555-561, 2005.

2. Yoo HS, Shin JW, Cho JH, Son CG, Lee YW, Park SY and Cho CK: Effects of Cordyceps militaris extract on angiogenesis and tumor growth. Acta Pharmacol Sin 25: 657-665, 2004.

3. Hattori M, Isomura S, Yokoyama E, Ujita M and Hara A: Extracellular trypsin-like proteases produced by Cordyceps militaris. J Biosci Bioeng 100: 631-636, 2005.

4. Park C, Hong SH, Lee JY, Kim GY, Choi BT, Lee YT, Park DI, Park YM, Jeong YK and Choi YH: Growth inhibition of U937 leukemia cells by aqueous extract of Cordyceps militaris through induction of apoptosis. Oncol Rep 13: 1211-1216, 2005.

5. Zhang G, Huang Y, Bian Y, Wong JH, Ng TB and Wagn H: Hypoglycemic activity of the fungi Cordyceps militaris, Cordyceps sinensis, Tricholoma mongolicum and Omphalia lapidescens in streptozotocin-induced diabetic rats. Appl Microbiol Biotechnol 72: 1152-1156, 2006.

6. Ohta Y, Lee JB, Hayashi K, Fujita A, Park DK and Hayashi T: In vivo anti-influenza virus activity of an immunomodulatory acidic polysaccharide isolated from Cordyceps militaris grown on germinated soybeans. J Agric Food Chem 55: 10194-10199, 2007.

7. Lee H, Kim YJ, Kim HW, Lee DH, Sung MK and Park T: Induction of apoptosis by Cordyceps militaris through activation of caspase-3 in leukemia HL-60 cells. Biol Pharm Bull 29: 670-674, 2006.

8. Xu FL, Lee YL, Tsai WY, Lin SJ, Yang ZQ, Yang CC, Liu HY, Cheng L, Xiao H and Wen L: Effect of cordycepin on Hantaan virus 76-118 infection of primary human embryonic pulmonary fibroblasts-characterization of apoptotic effects. Acta Virol 49: 183-193, 2005.

9. Nakamura K, Konoha K, Yoshikawa N, Yamaguchi Y, Kagota S, Shinozuka K and Kunitomo M: Effect of cordycepin (3'-deoxyadenosine) on hematogenic lung metastatic model mice. In Vivo 19: 137-141, 2005.

10. Nakamura K, Yoshikawa N, Yamaguchi Y, Kagota S, Shinozuka K and Kunitomo M: Antitumor effect of cordycepin (3'-deoxyadenosine) on mouse melanoma and lung carcinoma cells involves adenosine A3 receptor stimulation. Anticancer Res 26: 43-47, 2006. 
11. Yoshikawa N, Nakamura K, Yamaguchi Y, Kagota S, Shinozuka K and Kunitomo M: Antitumour activity of cordycepin in mice. Clin Exp Pharmacol Physiol 31 (Suppl 2): S51-S53, 2004.

12. Lee SJ, Kim SK, Choi WS, Kim WJ and Moon SK: Cordycepin causes p21WAF1-mediated G2/M cell-cycle arrest by regulating c-Jun N-terminal kinase activation in human bladder cancer cells. Arch Biochem Biophys 490: 103-109, 2009.

13. Zhou X, Luo L, Dressel W, Shadier G, Krumbiegel D, Schmidtke P, Zepp F and Meyer CU: Cordycepin is an immunoregulatory active ingredient of Cordyceps sinensis. Am J Chin Med 36: 967-980, 2008

14. Shin S, Lee S, Kwon J, Moon S, Lee S, Lee CK, Cho K, Ha NJ and Kim K: Cordycepin suppresses expression of diabetes regulating genes by inhibition of lipopolysaccharide-induced inflammation in macrophages. Immune Netw 9: 98-105, 2009.

15. Thomadaki H, Scorilas A, Tsiapalis CM and Havredaki M: The role of cordycepin in cancer treatment via induction or inhibition of apoptosis: Implication of polyadenylation in a cell type specific manner. Cancer Chemother Pharmacol 61: 251-265, 2008

16. Zhou X, Meyer CU, Schmidtke P and Zepp F: Effect of cordycepin on interleukin-10 production of human peripheral blood mononuclear cells. Eur J Pharmacol 453: 309-317, 2002.

17. Guo P, Kai Q, Gao J, Lian ZQ, Wu CM, Wu CA and Zhu HB: Cordycepin prevents hyperlipidemia in hamsters fed a high-fat diet via activation of AMP-activated protein kinase. J Pharmacol Sci 113: 395-403, 2010

18. Lomonosova E and Chinnadurai G: BH3-only proteins in apoptosis and beyond: An overview. Oncogene 27 (Suppl 1): S2-S19, 2008.

19. Seitz SJ, Schleithoff ES, Koch A, Schuster A, Teufel A, Staib F, Stremmel W, Melino G, Krammer PH, Schilling T and Müller M: Chemotherapy-induced apoptosis in hepatocellular carcinoma involves the p53 family and is mediated via the extrinsic and the intrinsic pathway. Int J Cancer 126: 2049-2066, 2010.

20. Lee SY, Debnath T, Kim SK and Lim BO: Anti-cancer effect and apoptosis induction of cordycepin through DR3 pathway in the human colonic cancer cell HT-29. Food Chem Toxicol 60: 439-447, 2013.

21. Lee HH, Park C, Jeong JW, Kim MJ, Seo MJ, Kang BW, Park JU, Kim GY, Choi BT, Choi YH and Jeong YK: Apoptosis induction of human prostate carcinoma cells by cordycepin through reactive oxygen species-mediated mitochondrial death pathway. Int J Oncol 42: 1036-1044, 2013.

22. Chen YH, Wang JY, Pan BS, Mu YF, Lai MS, So EC, Wong TS and Huang BM: Cordycepin enhances cisplatin apoptotic effect through caspase/MAPK pathways in human head and neck tumor cells. Onco Targets Ther 6: 983-998, 2013.

23. Sytwu HK, Liblau RS and McDevitt HO. The roles of Fas/APO-1 (CD95) and TNF in antigen-induced programmed cell death in T cell receptor transgenic mice. Immunity 5: 17-30, 1996.

24. Lien YC, Daosukho C and St Clair DK: TNF receptor deficiency reveals a translational control mechanism for adriamycin-induced Fas expression in cardiac tissues. Cytokine 33 226-230, 2006

25. Grunert M, Gottschalk K, Kapahnke J, Gündisch S, Kieser A and Jeremias I: The adaptor protein FADD and the initiator caspase- 8 mediate activation of NF- $\mathrm{KB}$ by TRAIL. Cell Death Dis 3: e414, 2012.
26. Saggioro FP, Neder L, Stavale JN, Paixão-Becker AN, Malheiros SM, Soares FA, Pittella JE, Matias CC, Colli BO, Carlotti CG and Franco M: Fas, FasL and cleaved caspases 8 and 3 in glioblastomas: A tissue microarray-based study. Pathol Res Pract 210: 267-273, 2014.

27. Kaufmann T, Strasser A and Jost PJ. Fas death receptor signalling: Roles of Bid and XIAP. Cell Death Differ 19: 42-50, 2012.

28. Vogel A, Aslan JE, Willenbring H, Klein C, Finegold M, Mount H, Thomas G and Grompe M: Sustained phosphorylation of Bid is a marker for resistance to Fas-induced apoptosis during chronic liver diseases. Gastroenterology 130: 104-119, 2006.

29. Schmich K, Schlatter R, Corazza N, Sá Ferreira K, Ederer M, Brunner T, Borner C and Mergort I: Tumor necrosis factor $\alpha$ sensitizes primary murine hepatocytes to Fas/CD95-induced apoptosis in a Bim- and Bid-dependent manner. Hepatology 53: 282-292, 2011.

30. Liu G, Wang T, Wang T, Song $\mathrm{J}$ and Zhou Z: Effects of apoptosis-related proteins caspase- 3 , Bax and $\mathrm{Bcl}-2$ on cerebral ischemia rats. Biomed Rep 1: 861-867, 2013

31. Hu Q, Cui X, Tao L, Xiu L, Wang T and Wang X: Staphylococcus aureus induces apoptosis in primary bovine mammary epithelial cells through Fas-FADD death receptor-linked caspase- 8 signaling. DNA Cell Biol 33: 388-397, 2014.

32. Jung EB and Lee CS: Baicalein attenuates proteasome inhibition-induced apoptosis by suppressing the activation of the mitochondrial pathway and the caspase-8- and Bid-dependent pathways. Eur J Pharmacol 730: 116-124, 2014.

33. Wang J and Li W: Discovery of novel second mitochondria-derived activator of caspase mimetics as selective inhibitor of apoptosis protein inhibitors. J Pharmacol Exp Ther 349: 319-329, 2014.

34. Gómez-Crisóstomo NP, López-Marure R, Zapata E, Zazueta C and Martínez-Abundis E: Bax induces cytochrome $c$ release by multiple mechanisms in mitochondria from MCF7 cells. J Bioenerg Biomembr 45: 441-448, 2013.

35. De Martino L, Marfé G, Longo M, Fiorito F, Montagnaro S, Iovane V, Decaro N and Pagnini U: Bid cleavage, cytochrome $c$ release and caspase activation in canine coronavirus-induced apoptosis. Vet Microbiol 141: 36-45, 2010.

36. Kumar P, Coltas IK, Kumar B, Chepeha DB, Bradford CR and Polverini $\mathrm{P}$ : $\mathrm{Bcl}-2$ protects endothelial cells against gamma-radiation via a Raf-MEK-ERK-survivin signaling pathway that is independent of cytochrome $c$ release. Cancer Res 67: 1193-1202, 2007.

37. Lei X, Chen Y, Du G, Yu W, Wang X, Qu H, Xia B, He H, Mao J, Zong W, et al: Gossypol induces Bax/Bak-independent activation of apoptosis and cytochrome $c$ release via a conformational change in Bcl-2. Faseb J 20: 2147-2149, 2006.

38. Hajiahmadi S, Panjehpour M, Aghaei M and Shabani M: Activation of $\mathrm{A} 2 \mathrm{~b}$ adenosine receptor regulates ovarian cancer cell growth: involvement of $\mathrm{Bax} / \mathrm{Bcl}-2$ and caspase- 3 . Biochem Cell Biol 93: 321-329, 2015

39. Dastjerdi MN, Valiani A, Mardani M and Ra MZ: Adenosine A1 receptor modifies P53 expression and apoptosis in breast cancer cell Mcf-7. Bratisl Lek Listy 117: 242-246, 2016.

40. Nagaya H, Gotoh A, Kanno T and Nishizaki T: A3 adenosine receptor mediates apoptosis in invitro RCC4-VHL human renal cancer cells by up-regulation AMID expression. J Urol 189: 321-328, 2013. 